\title{
Electrophysiological disturbances in heart failure
}

\author{
R W F Campbell
}

Cardiac arrhythmias are a frequent and important complication of cardiac failure regardless of aetiology. It might be expected that those afflicted would be aware of their occurrence, but surprisingly, even salvoes of ventricular tachycardia often are not perceived by patients. It has required 24 hour ambulatory electrocardiographic recordings to disclose the true prevalence of arrhythmias.

The typical arrhythmias complicating heart failure comprise atrial and ventricular extrasystoles, atrial fibrillation (which is arguably the most important arrhythmia), and short paroxysms of polymorphic ventricular tachycardia. Sustained regular narrow QRS tachycardias and monomorphic ventricular tachycardia are unusual. This spectrum of arrhythmias suggests that either triggered automaticity or complex functional re-entry are the more usual basic electrophysiological arrhythmogenic mechanisms in heart failure than is single circuit re-entry.

\section{Prognostic importance of arrhythmias in heart failure}

In many cardiovascular diseases, the impact of complicating arrhythmias extends beyond that of their symptomatic upset. A variety of ventricular arrhythmias are of prognostic importance in patients after a myocardial infarction, ${ }^{1}$ and in those with aortic stenosis ${ }^{2}$ or hypertrophic cardiomyopathy. ${ }^{3}$ Ventricular arrhythmias are also of prognostic importance in heart failure. ${ }^{45}$ Patients with high frequency ventricular extrasystoles fare more poorly than those with low frequency extrasystoles. ${ }^{5}$ The association, not surprisingly, raised the possibility that many patients with heart failure who died did so because of ventricular tachycardias. ${ }^{6}$ There is still great controversy surrounding this concept. It is certainly true that even in patients with heart failure, sudden unexpected and presumptively arrhythmic death occurs with surprising frequency. ${ }^{7}$ But in studies following up individual patients, although ventricular arrhythmias were common, and mortality high, mortality attributable to ventricular tachycardias was rare. ${ }^{8}$

University of Newcastle upon Tyne, Freeman Hospital, Newcastle upon Tyne R W F Campbell Correspondence to: Professor R W F Campbell, Academic Cardiology, Freeman Hospital, Fewcastle upon Tyne NE7 7DN. sion, but most available antiarrhythmic drugs depress left ventricular performance and are either relatively or absolutely contraindicated. ${ }^{9}$ In general, treatment is appropriate for only those arrhythmias, such as atrial fibrillation, which cause haemodynamic upset.

Antiarrhythmic drugs may be indicated in individual patients for the control of specific arrhythmias, ${ }^{10}$ but attempts to improve prognosis in heart failure by suppressing ventricular arrhythmias with antiarrhythmic treatment have been most disappointing. ${ }^{112}$ Middlekauff et al in a non-randomised observational study found one year survival rates of $76 \%$ in patients taking class $I$ antiarrhythmic treatment $v 86 \%$ for those receiving no antiarrhythmic treatment. ${ }^{12}$ Perhaps it is not surprising that class I antiarrhythmic drugs produced no benefit but it has been widely believed that amiodarone would prove to be an important intervention. ${ }^{13}$ Although the situation is far from proved, current evidence is not encouraging. Stewart et al in a placebo controlled randomised study showed no benefits of amiodarone treatment in a one year follow up of patients with heart failure and complicating ventricular arrhythmias. ${ }^{14}$ The Basel antiarrhythmic study of infarct survival was conducted in patients after an infarct and examined amiodarone $v$ conventional treatment $v$ no antiarrhythmic drug treatment in survivors of an acute myocardial infarction..$^{15}$ A significant benefit of amiodarone was shown. This finding was echoed by the Polish amiodarone study. ${ }^{16}$ In both studies a proportion of the enrolled patients had heart failure and it might be inferred that in this context of impaired left ventricular dysfunction, amiodarone might have benefits. A recent analysis of the BASIS study suggests not. Pfisterer and colleagues showed that in the BASIS study prognostic benefits from amiodarone accrued to those with ejection fractions (EFs) $>40 \%$ but in those with impaired left ventricular function (EF <40\%) amiodarone showed no benefits by comparison with control treatment. ${ }^{17}$

What lessons can we derive from these therapeutic findings in relation to the mechanisms of arrhythmias in heart failure? It would seem that in heart failure as with many other cardiac conditions, prognostically important cardiac arrhythmias are markers of risk rather than direct mechanisms of death. The failure of antiarrhythmic drugs to prevent mortality must mean either that death in patients with heart failure is not arrhythmically mediated, which is in keeping with some might be expected to have particularly serious consequences in those with impaired cardiac function and so merit enthusiastic suppres- 
suggestions, or else that currently available antiarrhythmic options are ineffective against fatal arrhythmic events. If this were true, it might suggest that the fundamental mechanism of arrhythmias in heart failure is different from that of the marker events as the marker events are suppressible.

\section{Electrophysiological abnormalities of heart failure}

Heart failure is not a specific disease. In that it is a syndrome complex secondary to a variety of cardiovascular diseases, these primary pathological events may in themselves create arrhythmias. When heart failure develops, a complex range of important and potentially arrhythmogenic phenomena occur. They include increased circulating catecholamines, ${ }^{18}$ electrolytic disturbances, ${ }^{19}$ and myocardial hypertrophy. ${ }^{20}$ Also, in most processes causing heart failure, fibrous tissue replaces functioning myocardium. The fibrosis may be relatively confluent as in myocardial infarction, be patchy as in the mottled infarct patterns of microembolic infarction, or may be dramatically inconsistent resembling that seen in hypertrophic cardiomyopathy. ${ }^{21}$

There is no specific electrophysiological signature of heart failure. Rather the electrophysiological abnormalities reflect the varying contributions both of the processes of damage and repair and of the reflex responses to the condition.

\section{CATECHOLAMINES}

Part of the neurohormonal response to heart failure is an increase in circulating catecholamines $^{22}$ that might, as in other cardiovascular pathological events, be expected to have an arrhythmogenic effect. Certainly the prognosis of heart failure is intimately linked with circulating plasma noradrenaline concentrations, ${ }^{18}$ but myocardial $\beta$ receptors are down regulated in the face of constant high circulating catecholamine concentrations. ${ }^{23}$ This might be interpreted as providing relative myocardial protection, but this is not proved and might in any case depend on the uniformity of expression of the remaining $\beta$ receptors.

\section{ELECTROLYTES}

Electrolytic derangements, principally those of potassium and magnesium, are common in heart failure either because of the basic disease process causing heart failure or more commonly, as a consequence of the treatment of heart failure with diuretics that cause loss of electrolytes. Low potassium concentrations may encourage triggered automatic behaviour but the effect of a low magnesium concentration is more controversial; it correlates with age and severity of heart failure but not with sudden death. ${ }^{24}$

\section{VENTRICULAR HYPERTROPHY}

Hypertrophy is increasingly recognised as an important component of the reflex changes associated with heart failure. Although it offers some mechanical advantages principally related to energy conservation, hypertrophy has been identified as an important adverse prognostic risk factor. ${ }^{25}$ Transventricular conduction times are slowed in the hypertrophied heart although conduction velocity is not necessarily impaired. In extreme cases, ventricular hypertrophy may outstrip available oxygen supply producing areas of focal ischaemia and thus creating electrical inhomogeneity.

\section{MYOCARDIAL STRETCH}

Excitation contraction feedback is receiving considerable attention. When myocardial cells are stretched their membrane potentials may become unstable and create triggered automatic arrhythmias. ${ }^{26}$

\section{FIBROSIS}

The implications of fibrosis in the myocardium are only now receiving attention. In hypertrophic cardiomyopathy, important changes in latency and cell to cell coupling have been shown, ${ }^{27}$ and these may eventually be correlated with prognosis. Fibrosis interferes with cell to cell transmission of the depolarising wave front.

\section{GAP JUNCTIONS}

There is evidence that in heart failure gap junctions may be deficient ${ }^{28}$ so interfering with cell to cell electrical transmission.

\section{Mechanisms of arrhythmias in heart failure}

Single circuit re-entry is a most uncommon mechanism of arrhythmias in patients with heart failure unless it is generated by the disease responsible for the heart failure. Single circuit re-entry is typified by the sustained monomorphic ventricular tachycardia that complicates the late period after infarction and by the reciprocating tachycardia of WolffParkinson-White syndrome. Most arrhythmias in heart failure are probably based on either interlacing wavelets of re-entry or triggered automaticity.

INTERLACING WAVELETS OF RE-ENTRY

Atrial fibrillation is probably the commonest arrhythmic complication of heart failure. Its basic mechanism has been postulated as interlacing wavelets of re-entry, ${ }^{29}$ a hypothesis that has been largely borne out by modern multipoint activation studies. ${ }^{30}$ Present day knowledge, supported by recent developments in the surgical management of atrial fibrillation, suggests that atrial fibrillation may not be a completely random process and further, that a relatively stable moderate number of circuits (6-10) may be responsible for the surface electrocardiogram. ${ }^{31}$ Based on the concept of wavelength, the emergence of atrial fibrillation may arise from reduced conduction velocity in the atrial myocardium allowing relatively small and multiple activation loops to be created within its available anatomy. Further, triggered automatic atrial extrasystoles may be a mechanism of creating electrical 
inhomogeneity in the atria, establishing a self perpetuating phenomenon manifest as the clinical arrhythmia.

\section{TRIGGERED AUTOMATICITY}

Triggered automaticity has been recognised as an experimental mechanism for arrhythmia but, with the possible exception of digitalis intoxication, no clinical arrhythmias had been shown to be due to this mechanism. Now there is growing belief that torsade de pointes is a triggered automatic arrhythmia. ${ }^{32}$ Furthermore, the typical ventricular tachycardias that complicate heart failure are relatively brief, irregular, polymorphic arrhythmias. They crudely share some of the characteristics of torsade de pointes and seem likely to be due to triggered automatic activity.

Therapeutic implications of mechanisms of arrhythmia for clinical management In the early stages of heart failure both the atrial and ventricular myocardium have relatively normal electrophysiological properties and have not yet undergone permanent damage. As heart failure becomes chronic, stretch, hypertrophy, and the activation of several deleterious neuroendocrine responses including increases of circulating noradrenaline bring into play a variety of arrhythmogenic factors that may be difficult or impossible to reverse. There is thus a strong case for early intervention in heart failure in an attempt to prevent these responses.

Arrhythmogenic manifestations in heart failure caused by electrolytic disturbances are readily amenable to management. Patients with heart failure are at serious risk of arrhythmias and scrupulous attention must be paid to preserving normal concentrations of electrolytes.

Remarkably little is understood about the benefits and detriments of increased concentrations of circulating noradrenaline in patients with heart failure. There is continuing research interest in the value of $\beta$ blockers prescribed to highly selected patients, and several studies have shown that for at least some, impressive benefits can be provided. ${ }^{33} 34$ This is of great interest particularly as $\beta$ blockers are one of the few interventions shown to improve prognosis for any cardiovascular disease, and their contribution in patients after a myocardial infarction is now well established. Moreover, in patients after a myocardial infarction retrospective analysis suggests that those patients with impaired left ventricular function may be those most likely to gain prognostic benefit. ${ }^{35} \beta$ Blockers are powerful antiarrhythmic drugs but their potentially deleterious effects in patients with heart failure brought about by their ability to block what may be a vital sympathetic drive demands that they be used with caution. ${ }^{36}$

Myocardial stretch encourages triggered automatic behaviour and it may be one of the stimuli for fibrosis. Stretch may also be involved in the altered function or disappearance of gap junctions. Myocardial stretch is most efficiently reduced by vasodilator treatment. Angiotensin converting enzyme (ACE) inhibitors have shown their ability to improve prognosis for patients with severe heart failure $^{37}$ and for patients with moderate heart failure, ${ }^{38}$ and have also shown benefits for those with asymptomatic left ventricular dysfunction. ${ }^{39}$ They have been shown to reduce ventricular extrasystolic activity, ${ }^{4041}$ and it was initially widely believed that ACE inhibitors might improve prognosis through protection from lethal arrhythmias. In the first cooperative north Scandinavian enalapril survival study (CONSENSUS I) mortality was reduced but there was no evidence that this was due to an antiarrhythmic effect of the ACE inhibitors. ${ }^{37}$ Indeed, there is only one study, the second Veterans Administration heart failure trial (V-HeFT II), which has shown a reduction of sudden, presumptively arrhythmic, death associated with ACE inhibitor treatment. ${ }^{42}$ Interestingly in that study, the effect was shown, not $v$ placebo, but $v$ patients treated with the combination of isosorbide dinitrate and hydralazine. Thus if this result is confirmed in other studies, it would suggest that vasodilatation alone is insufficient to produce an antiarrhythmic effect and that it needs the special properties of an ACE inhibitor as opposed to those of more general vasodilatation produced by isosorbide dinitrate and hydralazine. None the less, small studies have suggested that other vasodilators may modify arrhythmias..$^{43}$

\section{Contribution of specific diseases}

Diagnostic precision is increasing in patients presenting with heart failure. Although in a reasonable proportion an underlying disease can be identified, there is still an embarrassing number labelled as idiopathic dilated cardiomyopathy. As more is understood of the agents and infective particles able to inflict damage on the myocardium, a greater proportion of specific diagnoses will be made. There may be specific patterns of arrhythmia related to particular aetiologies of heart failure. There have been suggestions that the arrhythmias that complicate Chagas' disease are unique, ${ }^{45}$ and there is evidence that the electrophysiology of alcohol related heart muscle disease may be specific. ${ }^{46}$

In conclusion, every conceivable electrophysiological upset can occur in heart failure; there is no specific electrophysiological pattern associated with the syndrome. None the less, the process of arrhythmogenesis and heart failure has become easier to understand with growing recognition of triggered automatic arrhythmogenesis and the conditions necessary for interlaced wavelets of re-entry. Management strategies are turning from conventional drugs such as the class I antiarrhythmic agents to interventions that alter the loading conditions of the myocardium, principally the ACE inhibitors, or which alter neurohormonal responses, principally the $\beta$ blockers. Management also needs to be instituted early, much earlier than has been the 
case in the past, if the electrophysiological changes that cause irreparable damage are to be avoided. Such drastic changes in clinical practice will introduce new risks and problems but at present they offer a new hope for quality of life. The field is exciting but there are large gaps in our knowledge.

Clinical electrophysiological studies, despite their complexity, show remarkably little of what is happening in the myocardium at a cellular level. Complex invasive investigations are inappropriate for patients either in the early stages of heart failure or for those who are severely incapacitated. Much of our understanding of the abnormal electrophysiology of heart failure comes either from clinical deductions in the light of clinical electrophysiological experience or from experimental studies. Perhaps most difficult of all is to acknowledge that the electrophysiological milieu in heart failure is not static. It may change in a remarkably short time. Were the electrophysiology of the failing heart to be characterised at one point in time then it is conceivable that a relatively untoward event could turn a stable but abnormal situation into one that is suddenly fatal. An unexpected crisis that altered catecholamine concentrations or myocardial loading might be tolerated in the normal heart but in the failing heart could be the trigger for lethal arrhythmogenesis. Innovative clinical research is likely to produce the answers for clinical management in the next few years but it will be a long time before there are tests with sufficient precision and reliability for the management of individual patients.

1 Bigger JT, Fleiss JL, Kleiger R, Miller JP, Rolnitzky LM, and The Multicenter Post Infarction Research Group. The relationships among ventricular arrhythmias, left ventricular dysfunction, and mortality in the two years after myocardial infarction. Circulation 1984;69:250-8. Chizner MA, Pearle DL, de Leon AC. The natural histor of aortic stenosis in adults. Am Heart f 1980;99:419-24.
McKenna WJ, Harris L, Perez G, Krikler DM, Oakley C McKenna WJ, Harris L, Perez G, Krikler DM, Oakley C,
Goodwin JF. Arrhythmias in hypertrophic cardiomyopathy. II Comparison of amiodarone and verapamil in treatment. Br Heart f 1981;46:173-8.

4 Chakko S, DeMarchena E, Kessler KM, Myerburg RJ. Ventricular arrhythmias in congestive heart failure. $\mathcal{f}$ Clin Cardiol 1989;12:525-30.

5 Cleland JGF, Dargie HJ, Ford I. Mortality in heart failure: clinical variables of prognostic value. $\mathrm{Br}$ Heart $f$ 1987;58:572-82.

6 Packer M. Sudden unexpected death in patients with congestive heart failure: a second frontier. Circulation 1985;55:146-51.

7 Luu M, Stevenson WG. Diverse mechanisms of unexpected cardiac arrest in advanced heart failure. Circulation 1989;80:1675-80.

8 Maskin CS, Siskind SJ, LeJemtel TH. High prevalence of nonsustained ventricular tachycardia in severe congestive heart failure. Am Heart f 1984;107:896-901.

9 Bourke JP, Cowan JC, Tansuphaswadikul S, Campbell RWF. Antiarrhythmic drug effects on left ventricular performance. Eur Heart $\mathcal{F}$ 1987;8:105-11.

10 Brodsky MA, Allen BJ, Abate D, Henry WL. Propafenone therapy for ventricular tachycardia in the setting of congestive heart failure. Am Heart $\mathcal{F}$ 1985;110:794-9.

11 Chakko S, Gheorghiade M. Ventricular arrhythmias in severe heart failure: incidence, significance and effectiveness of therapy. Am Heart $\mathcal{1} 1985 ; 109: 497-504$.

12 Middlekauff HR, Stevenson WG, Saxon LA, Stevenson LW. Safest antiarrhythmic drug in advanced heart failure depends on heart failure etiology [abstract]. $\mathcal{F} A m$ Coll Cardiol 1992;19:78A.

13 Nicklas JM, McKenna WJ, Stewart RA, Mickelson JK, Das SK, Schork MA, et al. Prospective, double-blind, placebo-controlled trial of low-dose amiodarone in patients with severe heart failure and asymptomatic frequent ventricular ectopy. Am Heart $\mathcal{f} 1991$; 122:1016-21.
14 Stewart RA, McKenna WJ, Poloniecki JD, Michelson JK, Das SK, Morady F, et al. Prospective randomised double blind placebo controlled trial of low dose amiodarone in patients with severe heart failure and frequen ventricular extrasystoles. Br Heart $\mathcal{F}$ 1989;61:459.

15 Burkart FF, Pfisterer M, Kiowski W, Follath F, Burckhardt D, Jordi H. Effect of antiarrhythmic therapy on mortality in survivors of myocardial infarction with asymptomatic complex ventricular arrhythmias: Basel antiarrhythmic study of infarct survival (BASIS). $\mathcal{f} \mathrm{Am}$ Coll Cardiol 1990;16:1711-8.

16 Ceremuzynski L, Kleczar E, Krzeminska-Pakula M, Kuch J, Nartowicz E, Smielak-Korombel J, et al. Effect of amiodarone on mortality after myocardial infarction: a double-blind, placebo-controlled, pilot study. $\mathcal{F} \mathrm{Am}$ Coll Cardiol 1992;20:1056-62.

17 Pfisterer M, Kiowski W, Burckhardt D, Follath F, Burkart F. Beneficial effect of amiodarone on cardiac mortality in patients with asymptomatic complex ventricular arrhythmias after acute myocardial infarction and preserved but not impaired left ventricular function. $A m \mathcal{F}$ Cardiol 1992;69:1399-402.

18 Cohn JN, Levine TB, Olivari MT, Garberg V, Lura D, Francis GS, et al. Plasma norepinephrine as a guide to prognosis in patients with chronic congestive heart failure. N Engl $\mathcal{F}$ Med 1984;311:819-23.

19 Wester PO. Electrolyte balance in heart failure and the role for magnesium ions. Am $\mathcal{F}$ Cardiol 1992;70:44C-49C.

$20 \mathrm{Katz}$ AM. The heart in congestive failure. Cardioscience 1990;1:3-6.

21 Davis MJ. The current status of myocardial disarray in hypertrophic cardiomyopathy. Br Heart $\mathcal{f} 1984 ; 51$ : 361-74.

22 Francis GS. Neuroendocrine manifestations of congestive heart failure. Am $\mathcal{f}$ Cardiol 1988;62:9A-13A

23 Bristow MR, Ginsberg R, Minobe W, Cubiccioti RS Sageman WS, Lurie K, et al. Decreased catecholamine sensitivity and beta-adrenergic-receptor density in failing human hearts. N Engl f Med 1982;307:205-11.

24 Eichhorn EJ, Tandon PK, DiBianco R, Timmis GC Fenster PE, Shannon J, Packer M, on behalf of the PROMISE Study Investigators and Coordinators. Clinical and prognostic significance of serum magnesium concentration in patients with severe chronic congestive heart failure: the PROMISE Study. $7 \mathrm{Am} \mathrm{Coll}$ Cardiol 1993;21:634-40.

25 Frohlich ED. Left ventricular hypertrophy: an independent factor of risk. Cardiovascular Clinics 1990;20:85-95

26 Dean JW, Lab MJ. Arrhythmia in heart failure: role of mechanically induced changes in electrophysiology. Lancet 1989;i:1309-12.

27 Saumarez RC, Camm AJ, Panagos A, Gill JS, Stewart JT, de Belder MA, et al. Ventricular fibrillation in hypertrophic cardiomyopathy is associated with increased fractionation of paced right ventricular electrograms. Circulation 1992;86:467-74.

28 De Maziere AM, Scheuermann DW. Structural changes in cardiac gap junctions after hypoxia and reoxygenation: a quantitative freeze-fracture analysis. Cell Tissue Res 1990;261:183-94.

29 Moe GK. Evidence for re-entry as a mechanism of cardiac arrhythmias. Rev Physiol Biochem Pharmacol 1975;72:55-81.

30 Allessie MA, Janse MJ. Atrial fibrillation: is our electrophysiological understanding on the right wavelength? physiological understanding on the right wavelength?
In: Campbell RWF, Janse MJ, eds. Cardiac arrhythmias: the management of atrial fibrillation. Berlin: Springerthe management of

31 Cox JL, Canavan TE, Schuessler RB, Cain ME, et al. The surgical treatment of atrial fibrillation. II. Intraoperative electrophysiologic mapping and description of the electrophysiologic basis of atrial flutter and atrial fibrillation. f Thorac Cardiovasc Surg 1991;101:402-26.

32 Kadish AH, Morady F. Torsade de Pointes. In: Zipes, Jalife J, eds. Cardiac electrophysiology-from cell to bedside. Philadelphia: W B Saunders, 1990;605-10.

33 The German and Austrian Xamoterol Study Group. Double-blind placebo-controlled comparison of digoxin and xamoterol in chronic heart failure Lancet 1988;1:489-93.

34 Waagstein F, Hjalmarson A, Varnauskas E, Wallentin I Effect of chronic beta-adrenergic receptor blockade in congestive cardiomyopathy. Br Heart $\mathcal{f} 1975 ; 37$ : congestive

35 Furberg CD, Hawkins $M$, Lichstein E, for the $\beta$ Blocker Heart Attack Trial Study Group. Effect of propranolol in post infarction patients with mechanical or electrical complication. Circulation 1984;69:761-5.

36 The Xamoterol in Severe Heart Failure Study Group Xamoterol in severe heart failure. Lancet 1990;336:1-6.

37 The CONSENSUS Trial Study Group. Effects of enalapril on mortality in severe congestive heart failure: results of the co-operative north Scandinavian enalapril survival study (CONSENSUS). $N$ Engl $f \mathrm{Med}$ 1987;316:1429-35.

38 Pfeffer MA, Braunwald E, Moye LA, Basta L, Brown EJ $\mathrm{Jr}$, Cuddy TE, et al. Effects of captopril on mortality and morbidity in patients with left ventricular dysfunction after myocardial infarction. N Engl $\mathcal{F} \mathrm{Med}$ 1992;327:669-77.

39 The SOLVD Investigators. Effect of enalapril on mortality and the development of heart failure in asymptomatic and the development of heart failure in asymptomatic
patients with reduced left ventricular ejection fractions. patients with reduced left ventricu

40 Webster MWI, Fitzpatrick MA, Nicholls MG, Ikram H, 
Wells JE. Effect of enalapril on ventricular arrhythmias in congestive heart failure. Am F Cardiol 1985;56:566-9. 41 Cleland JGF, Dargie HT, Hodsman GP, Ball SG Robertson JIS, Morton J, et al. Captopril in heart failure-a double blind controlled trial. Br Heart $\%$ ure-a double

42 Cohn JN, Johnson G, Ziesche RN, Cobb F, Francis G, Tristani F, et al. A comparison of enalapril with hydralazine-isosorbide dinitrate in the treatment of chronic congestive heart failure. $N \mathrm{Engl} f \mathrm{Med}$ 1991;325:303-10.

43 Gnecchi M, DeMarzio P, Morelli S, Aguglia F.
Suppression of complex ventricular arrhythmias by isosorbide dinitrate in a case of congestive heart failure. Cardiologia 1985;30:401-4.

44 Bussmann WD, Haller M. Possible evidence for a reduction of early and late mortality during nitroglycerin therapy in acute myocardial infarction. Klin Wochenschr apy in acute myor

45 Rosenbaum MB. Chagasic myocardiopathy. Prog Cardiovasc Dis 1964;7:199-221.

46 Day CP, James, OF, Butler TJ, Campbell RWF. QT prolongation and sudden cardiac death in patients with alcoholic liver disease. Lancet 1993;341:1423-8. 